\title{
Cyproterone acetate-ethinyl estradiol use in a 23-year-old woman with stroke
}

\author{
Julie Kromm MD, Thomas Jeerakathil MD
}

Competing interests: Thomas Jeerakathil received funds from BristolMyers Squibb and Pfizer for attending an advisory board meeting about an unrelated medication in 2011. None declared by Julie Kromm.

This article has been peer reviewed.

The authors have obtained patient consent.

Correspondence to: Thomas Jeerakathil, thomasj@ualberta.ca

CMAJ 2014. DOI:10.1503 /cmaj.130579
$\mathrm{A}$ 23-year-old healthy fitness instructor was prescribed Diane-35 (cyproterone acetate-ethinyl estradiol) for acne. Three weeks later, she suddenly lost the ability to speak. She arrived at the hospital 2 hours and 45 minutes after symptom onset. Stroke causing nonfluent aphasia was diagnosed. After exclusion of any contraindications, she was given an infusion of intravenous tissue plasminogen activator.

Computed tomography (CT) of her brain showed small hypodensities in the left insular cortex and left frontal white matter. Brain magnetic resonance imaging (MRI) confirmed small patchy infarctions in the same areas (Figure 1). A thorough etiologic work-up included MR angiography of the intracranial vessels; contrastenhanced MR angiography of the aortic arch and neck vessels; four-vessel cerebral angiography; transesophageal echocardiography; Holter monitoring; antiphospholipid antibody and lupus anticoagulant; and fasting lipids, glucose and homocysteine. The results of these investigations were normal. On further questioning, the patient stated that she was not taking other medications or recreational drugs.

Therapy with cyproterone acetate-ethinyl estradiol (CPA-EE) was discontinued, and nonhormonal contraception was recommended. She continued to take clopidogrel (which had been started 24 hours after thrombolysis) and was discharged home with only subtle findings on examination. She has been free of any recurrent

events over the seven-year period since her stroke and has fully recovered.

According to the World Health Organization's criteria for causality in pharmacovigilance, ${ }^{1}$ our case demonstrates a "probable" link between CPA-EE and arterial stroke. The designation of "probable" refers to a clinical event with a reasonable temporal relation to drug administration that is not better explained by concurrent disease or drug use, and that follows a clinically reasonable response on withdrawal. ${ }^{1}$ Our patient's event occurred three weeks after she started taking CPA-EE, no other etiology could be documented and no recurrent events have occurred within seven years after withdrawal of the medication. We reported the case to the Canada Vigilance Program.

\section{Discussion}

Cyproterone acetate-ethinyl estradiol is a compound containing $2 \mathrm{mg}$ of cyproterone acetate (CPA) and $35 \mu \mathrm{g}$ of ethinyl estradiol (EE). It is marketed under various names worldwide. In Canada, its brand names include Diane-35, Cyestra-35 and Novo-Cyproterone/Ethinyl Estradiol. It has potent antiandrogenic, progestogenic and antigonadotropic activity. ${ }^{2}$ The CPA component of the compound suppresses ovarian androgen synthesis and secretion, and also blocks androgen receptors. ${ }^{2}$ Ethinyl estradiol increases sex hormone-binding globulin, which thus reduces circulating levels of free androgens. ${ }^{2}$

\section{History}

Cyproterone acetate-ethinyl estradiol was approved in Europe (under the brand name Diane35 ) in 1985, seven years after the approval of a similar agent called Diane (which contains a higher dose of estrogen). ${ }^{3}$ It was then marketed in Europe, Asia and Latin America for both contraception and as an acne treatment. ${ }^{3}$ In 1994, a German woman who had been using the agent 
for contraception for 14 years died of liver cancer. ${ }^{4}$ This led to a safety review by drug regulators in Germany and the eventual restriction of the use of this agent throughout Europe as a second-line agent for women with severe acne who display signs of hormonal imbalance. ${ }^{3}$ The drug obtained approval in Canada in 1998. The United States has never approved its licensing.

\section{Indications and usage in Canada}

In Canada, CPA-EE is indicated as a second-line agent for the treatment of hirsutism and severe acne that is unresponsive to other available treatments. ${ }^{5,6}$ Although guidelines do not suggest limiting the duration of treatment, the product monograph suggests that exposure to this compound be minimized and that it should be discontinued " 3 to 4 cycles after signs have completely resolved."' Although CPA-EE is not recommended solely for contraception, it will prevent ovulation when administered in a cyclical manner and provide reliable contraception if taken as recommended for approved indications. ${ }^{2}$ Despite these recommendations and several international and Canadian safety advisories, Mintzes and colleagues ${ }^{7}$ found that about half of CPA-EE prescriptions in Canada were for offlabel indications.

\section{Adverse effects}

There are numerous adverse effects of CPA-EE, which are of mild to moderate severity. These include dysmenorrhea and menorrhagia; breast tenderness; headache; gastrointestinal upset (e.g., nausea or abdominal pain); and psychiatric adverse effects (e.g., depression and reduced libido). ${ }^{2}$ Postmarketing reports of suspected adverse reactions include renal failure; liver disease, including nodular hyperplasia, adenoma, hepatocellular carcinoma; and systemic lupus erythematosus. ${ }^{8}$ The most common serious adverse reaction is venous thromboembolism.

\section{Relation with thrombosis}

The relation between combined hormonal contraceptives and thrombosis has been well documented. Following the introduction of the firstgeneration combined contraceptive agents (containing high levels of estrogen and progesterone) in the 1950s, it was found that high levels of estrogen were associated with both venous and arterial thromboembolism. Second-generation oral contraceptives introduced in the 1970s contained different progestins (i.e., synthetic progesterones, including levonorgestrel and norgestrel), combined with lower-dose EE. A third generation was introduced in the 1980s and contained newer progestins (e.g., desogestrel, gestodene and norgestimate). Most recently, a fourth-generation combined hormonal contraceptive containing drospirenone was launched in the 2000s. Cyproterone acetate-ethinyl estradiol is not included in this classification. Despite the formulation containing EE, its other active agent, CPA, is considered a synthetic steroid with potent antiandrogen, progestogenic and antigonadotropic activity. ${ }^{2}$

Although lowering the dose of estrogen in combined hormonal contraceptives has reduced the risk of thrombosis, it has not eliminated it. Estimates vary between studies; however, with progestogen type controlled for, as much as a sixfold increased risk of venous thromboembolism has been found among users of combined contraceptive pills containing more than $50 \mu \mathrm{g}$ of $\mathrm{EE}$, and as much as a threefold increased risk has been found for pills containing less than $50 \mu \mathrm{g}$ of EE, compared with nonusers. ${ }^{9}$ Using a baseline risk of venous thromboembolism among nonusers of similar age to our patient (20-24 yr) of 21/100 000 person-years, the number needed to harm $(\mathrm{NNH})$ per year of treatment for the corresponding EE doses is calculated to be 952 (> $50 \mu \mathrm{g} \mathrm{EE})$ and $2381(<50 \mu \mathrm{g} \mathrm{EE}){ }^{9}$

With regard to arterial thromboembolism, Lidegaard and colleagues ${ }^{10}$ found relative risks of

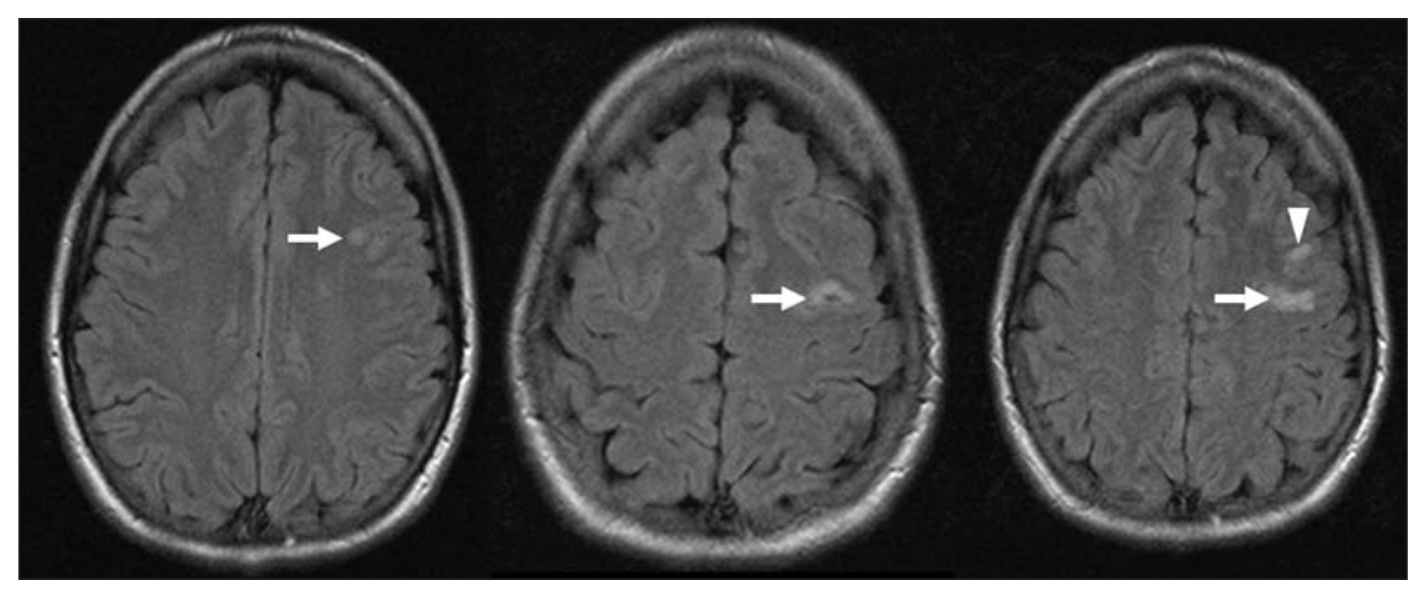

Figure 1: Magnetic resonance image of the brain showing infarctions involving the left insular cortex (arrow head) and left frontal white matter (arrows), in a 23-year-old woman with stroke causing nonfluent aphasia. 
stroke of 1.60 (95\% confidence interval [CI] 1.371.86; NNH 29 762), 1.75 (95\% CI 1.61-1.92; $\mathrm{NNH} 23$ 810) and 1.97 (95\% CI 1.45-2.66; NNH 18409 ) among patients taking combined hormonal contraceptives containing $\mathrm{EE}$ at a dose of $20 \mu \mathrm{g}, 30-40 \mu \mathrm{g}$ and $50 \mu \mathrm{g}$, respectively, compared with nonusers. The corresponding relative risks for myocardial infarction were found to be $1.40(95 \%$ CI 1.07-1.81; NNH 357 143), 1.88 (95\% CI 1.662.13; NNH 162338 ) and 3.73 (95\% CI 2.78-5.00; $\mathrm{NNH} 52$ 329). ${ }^{10}$ We calculated the above $\mathrm{NNH}$ values per year of treatment using baseline risks in our patient's age group of 5.6/100 000 personyears for stroke and $0.7 / 100000$ person-years for myocardial infarction.

It also appears that the progesterone component of these compounds may play a role in thrombosis. Recent studies have shown that, when controlling for estrogen dose, there is a two- to threefold increased risk of venous thromboembolism among users of combined hormonal contraceptives containing norethisterone, levonorgestrel or norgestimate, compared with nonusers (NNH 2381-4762). ${ }^{9,11}$ The same studies showed a four- to sixfold increase in venous thromboembolism among users of combined products containing desogestrel, gestodene, drospirenone, and among users of the contraceptive vaginal ring, compared with nonusers ( $\mathrm{NNH}$ 952-1587). ${ }^{9,11}$ However, progestin subtypes seem to convey a small (and, at times, statistically nonsignificant) difference in risk when it comes to arterial thromboembolism. ${ }^{10}$

It seems likely that CPA-EE also increases the risk of thrombosis. The relative risk of venous thromboembolism among users of CPAEE compared with nonusers is 6.35 (95\% CI 5.09-7.93), and the NNH is calculated to be 890. ${ }^{9}$ The relative risk and calculated NNH is 1.4 (95\% CI $0.97-2.03 ; 44643)$ and 1.47 (95\% CI $0.83-2.61 ; 303$ 951) for ischemic stroke and myocardial infarction, respectively. ${ }^{10}$ The relative risk of arterial events, although not statistically significant, is roughly proportional to rates seen with other combined hormonal contraceptives. ${ }^{10}$ The relative risk of venous thromboembolism is comparable to that of most third- and fourthgeneration combined hormonal contraceptives, and double that of second-generation hormonal contraceptives. ${ }^{9,11}$

It has been proposed that the observed difference in thrombosis risk between agents containing different progestogens is the total estrogenicity of the combined product. Estrogenicity is determined by both the dose of EE and the type of progestogen used. Sex hormone-binding globulin can be used as a marker of estrogenicity, because the hormone levels rise in states of high estrogen. Cyproterone acetate-ethinyl estradiol raises the levels of sex hormone-binding globulin by $300 \%-400 \%$ compared with a $50 \%$ increase caused by levonorgestrel preparations, which are known to have the lowest risk of thrombosis. ${ }^{11}$ This excessive rise in estrogenicity caused by CPA-EE likely increases the risk of thrombosis through various effects on the coagulation pathway, including reduction of the activity of various coagulation inhibitors (e.g., antithrombin, protein $\mathrm{C}$ and tissue factor pathway inhibitor); increased levels of coagulation factors, including II, VII, VIII and X; and increased platelet aggregation. ${ }^{12}$

\section{Recent developments and debate}

Franks and colleagues ${ }^{13}$ suggest the removal of "unnecessary restrictions" on the use of CPA$\mathrm{EE}$ for women with polycystic ovary syndrome. They argue that the risk of venous thromboembolism related to CPA-EE is no greater than that due to third-generation combined hormonal contraceptives.

On Jan. 30, 2013, the French National Agency for Medicines and Health Products Safety suspended sales of CPA-EE because of its connection with at least four deaths from venous thromboembolism in the previous 25 years. ${ }^{14}$ Health Canada has on several occasions released safety advisories about the increased risk of venous thromboembolism among users of CPA-EE. ${ }^{15,16}$ After suspension of the drug in France, both Health Canada and the European Medicines Agency began reviewing the medication. ${ }^{15}$ On May 17, 2013, Health Canada released a statement (similar to that of the European Medicines Agency) that, based on the available scientific literature, "the drug's benefits continue to outweigh its risks, when used as authorized." 15 The statement reports that CPA-EE

is approved for the temporary treatment of severe acne - with associated symptoms of high levels of male hormones ... - in women who are unresponsive to other available treatments. It should not be used in patients with a history that puts them at risk for blood clots, and is not approved for use as an oral contraceptive. ${ }^{15}$

\section{Conclusion}

Cyproterone acetate-ethinyl estradiol, like many other hormonal medications, has been shown to increase the risk of venous thromboembolism. Although a corresponding risk of arterial thromboembolism has not been as well established, our case provides evidence for a probable link between stroke and CPA-EE. However, given the much higher relative risk of venous thromboembolism compared with that of arterial 
thromboembolism, coupled with a higher baseline risk in the population that uses this agent, the venous risk tends to convey more harm than the arterial risk. When used appropriately as a second-line agent for a short duration to treat severe acne in women with other signs of androgenicity, the risk-benefit profile is favourable. However, clinicians should reconsider the offlabel use of this medication, because safer interventions exist for contraception and the treatment of mild to moderate acne.

\section{References}

1. The Uppsala Monitoring Centre. Safety monitoring of medicinal products: guidelines for setting up and running a pharmacovigilance centre. Uppsala (Sweden): World Health Organization; 2000. Available: http://apps.who.int/medicinedocs/en/d/Jh2934e/ (accessed 2013 Apr. 28).

2. Diane-35 [product monograph]. In: Compendium of pharmaceuticals and specialties. Ottawa (ON): Canadian Pharmacists Association; 2008. p. 686-8.

3. Mintzes B. Drug regulatory failure in Canada: the case of Diane-35. Toronto $(\mathrm{ON})$ : Women and Health Protection; 2004. Available: www.whp-apsf.ca/en/documents/diane35.html\#1 (accessed 2013 Oct. 1).

4. Rüdiger T, Beckmann J, Wueisser W. Hepatocellular carcinoma after treatment with cyproterone acetate combined with ethinyloestradiol. Lancet 1995;345:452-3.

5. Claman P. SOGC clinical practice guidelines: hirsutism evaluation and treatment J Obstet Gynaecol Can 2002;24:62-73.

6. Madden WS, Landells ID, Poulin Y, et al. Treatment of acne vulgaris and prevention of acne scarring: Canadian consensus guidelines. J Cutan Med Surg 2000;4(Suppl 1):S2-13.

7. Mintzes B, Morgan S, Bassett KL. Medicine by media: Did a critical television documentary affect the prescribing of cyproteroneestradiol (Diane-35)? CMAJ 2005;173:1313-5.
8. Health Canada. Canada Vigilance Adverse Reaction Online Database. Ottawa (ON): Health Canada; 2013. Available: www .hc-sc.gc.ca/dhp-mps/medeff/databasdon/index-eng.php (ac cessed 2013 Oct. 1)

9. Lidegaard $\varnothing$, Nielsen LH, Skovulund CW, et al. Risk of venous thromboembolism from use of oral contraceptives containing different progestogens and oestrogen doses: Danish cohort study, 2001-9. BMJ 2011;343:d6423.

10. Lidegaard $\varnothing$, Løkkegaard E, Jensen A, et al. Thrombotic stroke and myocardial infarction with hormonal contraception. $N$ Engl J Med 2012;366:2257-66.

11. Lidegaard Ø, Milsom I, Geirsson RT, et al. Hormonal contraception and venous thromboembolism. Acta Obstet Gynecol Scand 2012;91:769-78

12. Zakharova MY, Meyer RM, Brandy KR, et al. Risk factors for heart attack, stroke, and venous thrombosis associated with hormonal contraceptive use. Clin Appl Thromb Hemost 2011;17:323-31.

13. Franks S, Layton A, Glasier A. Cyproterone acetate/ethinyl estradiol for acne and hirsutism: time to revise prescribing policy. Hum Reprod 2008;23:231-2.

14. Lowes R. France to suspend sale of Diane 35. Medscape; 2013 Available: www.medscape.com/viewarticle/778499 (accessed 2013 Apr. 30).

15. Health Canada's review of Diane-35 supports current labelling and use. Ottawa (ON): Health Canada; 2013. Available: healthy canadians.gc.ca/recall-alert-rappel-avis/hc-sc/2013/29283a-eng.php (accessed 2013 Oct. 1)

16. Wooltorton E. Diane-35 (cyproterone acetate): safety concerns. CMAJ 2003;168:455-6.

Affiliation: Division of Neurology, Department of Medicine, University of Alberta, Edmonton, Alta.

Contributors: Both authors drafted and revised the article, and approved the version submitted for publication.

\section{Patient and physician resource}

Canada Vigilance Program: www.hc-sc.gc.ca/dhp -mps/medeff/vigilance-eng.php

\section{Call for papers: CMAJ Holiday Reading} $\ldots \ldots \ldots \ldots \ldots \ldots \ldots \ldots \ldots \ldots \ldots$

'Twas months before the holidays and all through CMAJ house not a submission was stirring, making editors grouse. "Holiday Reading time is nigh!" they cried in despair, in hopes that your papers soon would be there.

Submit your brilliant, missives, rigorous research (based on real data) on quirky topics or holiday-themed visuals at http://mc.manuscriptcentral.com/cmaj. Nonresearch submissions should be no longer than 1200 words. For information, contact barbara.sibbald@cmaj.ca.

Deadline: October 1, 2014

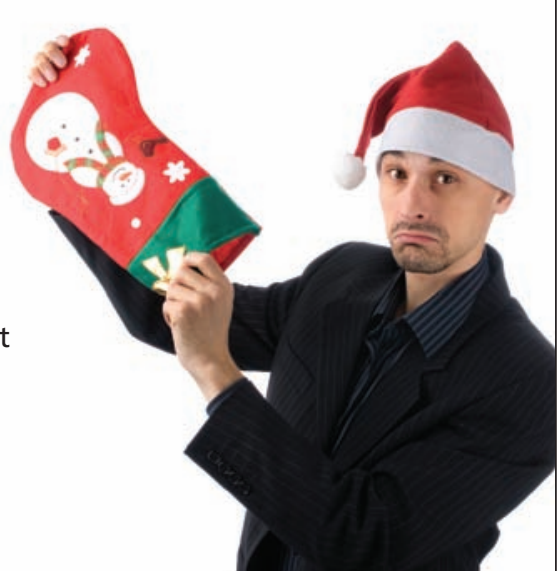

